Special Education Practices for Children with Autism Spectrum Disorders in the UK and Egypt: A comparative Study

Dr. Viola Mounir Abdou Mansour \& Dr. Ereny Samir Gobrial 


\title{
Special Education Practices for Children with Autism Spectrum Disorders in the UK and Egypt: A comparative Study
}

\author{
Dr. Viola Mounir Abdou Mansour \\ Lecturer of Comparative Education \&Educational Administration, College of \\ Education, Zagazig University, Egypt, \\ Drviolamounir@yahoo.com
}

\begin{abstract}
Dr. Ereny Samir Gobrial
Associate Professor Mental Heahlt College of Education, Zagazig University, Egypt, Ereny.gobrial@hotmail.co.uk
\end{abstract}

Received in June 1st, 2021

Accepted in September 25, 2021

\begin{abstract}
This study aims to compare the development of special education practices for children with autism spectrum disorders (ASD) in the UK and Egypt and gain an understanding of those factors that enhance special education in both countries. The study applies a comparative framework method. The findings provide a better understanding of special education practices and factors that enhanced the special education for ASD across the two countries. The findings reveal that special education practice in Egypt was hindered by low economic status, scarcity of cultural awareness, inadequate financial support and absence of education policy for ASD. While, in the UK education policy, cultural awareness, economy, and scientific technology have been identified as important enhancing factors for special education. The study suggests some recommendations for developing special education for ASD in Egypt.
\end{abstract}

Keywords: Autism spectrum disorders, Mothers, Special Education, Egypt, UK. 


\section{Introduction}

Special education (SE) for children with disabilities is grounded in the United Nations (UN) convention on the right of the child and the Salamanca framework for special education needs (SEN). Convention Article 26 of the UN has emphasized that children with disabilities are entitled to their basic human rights and have equal opportunity to be educated and live like other children (UNICEF 2014; UNICEF 1989). The Salamanca has affirmed the UN declaration that everyone has the right to education (UNESCO 1994).

Increasing the prevalence of children with autism spectrum disorders (ASD) is of interest to professionals of SE all over the world. Recent estimates of the prevalence of ASD indicated that 1:58 children are affected (CDC 2020). The prevalence of ASD in Europe has increased rapidly, due to an increased awareness of autism and hence an increased likelihood of the condition being diagnosed (Chiarotti and Venerosi 2020). Data suggests that around 700,000 individuals have ASD in the UK, including 1/100 children with an ASD diagnosis (BMA 2020). There are no accurate epidemiological data for ASD in Egypt (Taha \& Hussein 2014). However, available data indicates that about 1:160 children have ASD in Egypt, according to the Social Solidarity Ministry.

This data suggests increasing rates of children with ASD in every society. Hence, increasing demand for the educational system and how to best provide education for those children. There is an urgent need for a comprehensive educational practice to support children with ASD and support teachers with best practices based on resources and information (National Education Association 2003). Receiving the right education that meets the special needs of exceptional individuals makes tangible improvements in the lives of those individuals and their families. And yet, children with ASD in Egypt as one of the low-and middle-income countries (LMICs) experience poor education and encounter major barriers in accessing education. The majority of children with ASD remain at home uneducated (Gobrial 2018; Omar et al. 2017; Costandi 2011). Special schools for ASD are scarce in Egypt. As a result, this contributes to the unmet needs of pupils with ASD in Egypt, which could have a dramatic impact on the child 
and family's well-being (Gobrial 2018; Taha \& Hussein 2014). Further challenges include scarce knowledge of ASD, scarcity of professionals, barriers to diagnosis and treatment, limited resources for ASD and lack access to intervention services (Ibrahim et al. 2020; Gobrial, McAnelly \& Shannon 2019; Ghoneim 2014; Gobrial 2012; Jenkins, Heshmat, Loza, Siekkonen \& Sorour 2010).

The Ministry of education has taken a number of measures to support children with special needs, including training teachers of special education schools and teachers of inclusive educationand. Recently, a new undergraduate course for special education has launched in Egypt, through the new Faculty of Disability Sciences and Rehabilitation in Beni Suef and Zagazig universities and Misr University for sciences and technology (Gobrial, McAnelly \& Shannon 2019). These faculties offer a unique programme to prepare teachers to gain a firm grounding of knowledge and skills to special education. Furthermore, special training was provided for 70 thousand teachers in schools of public education and technical education in which the inclusion education was established including training for teaching pupils with ASD.

Despite that, the current situation in Egypt identifies a gap and reflects the need for SE practice for children with ASD. Given that children with ASD find it particularly challenging to enroll in the education system in Egypt, developing a quality education is vital for these children.

Consistent with the development and global interest in the field of SE, it has become imperative to pay attention to SE for children with ASD. Identification of experiences, models and practices in developed countries is important as it contributes to awareness and recognition of how other models can enrich local practices and policies (Courtenay 2018). Hence, it is necessary to get acquainted with successful international experiences and try to formulate a proposed scenario for implementation in Egypt.

There has been scant research into the SE practices for ASD in Egypt. Analysis and understanding of the specifics of education of any country is almost impossible without comparison (Jovanovic \& Ciric 2017) Hence, it is crucial to investigate how 
developed countries have successfully developed and established education for ASD. In this context, this study aims to compare the development of special education practices for ASD in Egypt and the UK, in order to reveal the factors that enhance the SE practices in both countries.

\section{Educational practice for ASD in Egypt}

The education system in Egypt runs by the government. It is free and compulsory for nine academic years for all children aged between 5-14 years. Although significant progress has been made to improve the education system, the quality of educational experiences remains low and unequally distributed (World Bank 2007).

There are three crucial obstacles that impacted SE for children with ASD in Egypt. First, special schools for children with ASD are scarce. There are a few private schools and private day-care centers which are available only in Cairo and major cities. Moreover, a private school that admits children with ASD is very costly and parents invariably find it difficult to sustain and accept mild cases only (Meguid 2014). Second, children who can make it into private school need to be accompanied by a teaching assistant. Parents are obligated to find a teaching assistant and pay the fees in addition to the school admission fees (with a minimum 1000L.E. per month, which consists of $50-60 \%$ of household income as average wage is 2600 L.E.) (Fathie 2016). Third, the inclusion classroom for children with disabilities are limited for pupils with ASD, however, pupils with ASD can enroll in special school for intellectual disabilities through inclusion education.

Inclusion education (IE) refers to the integration of children with SEN with their peers in a classroom or a provision in mainstream school (Maciver et al. 2018; DoE 2001). In the context of IE, children with disabilities are seen as paramount and enrolment of pupils with ASD remains limited. IE in a regular school in Egypt is subject to some criteria including children with mild disability (IQ between 65 and 84); excludes children with multiple disabilities; restricting the admission of children with disabilities to $10 \%$ of the total number of children in the classroom, and to a maximum of four children with disabilities in a classroom, according to Ministerial decision No.42 
for 2015. Furthermore, teachers have not received adequate training to deal with the special needs of children with ASD and lack the enthusiasm required for inclusion in regular classes (Ghoneim 2014). This highlights the need to develop SE practice for children with ASD in Egypt.

Although Egypt has positive innovations in establishing SE for major types of disabilities, schools for pupils with ASD are scarce. There is no special education policy that is focused on pupils with ASD. There is still an urgent need to advance the field of SE for children with disabilities in general and ASD specifically. Egypt still has a long way to go in developing effective and affordable education for ASD. Education is vital to develop their skills, abilities and quality of life, not only academically, but also a comprehensive development of various aspects in life. Hence, education policy in Egypt is urgently needed to be drafted to better support students with ASD.

\section{Educational practice for ASD in the UK}

The education system in the UK is compulsory and free for all children aged between 5-16 (Schools and Education Gov.uk. https://www.gov.uk/types-of-school. accessed 14 Mar. 2021).

The Warnock Report was a landmark in the development of policy on SE in The UK (Warnock 1978). The IE has promoted an increasing number of students with SEN. This includes a provision for children with ASD in a mainstream school (DoE 2001). The inclusion development program is part of the Government's strategy for children with SEN, which aims to help teachers and practitioners to enhance the skills needed for the early identification and support of children with high incidence needs (DoE 2009).

The educational practice for ASD in the UK is an adaptation of several approaches (e.g., computer-assisted learning, Hanen program, Lovaas programs, Waldon approach, Makaton signing and symbols message, music therapy, Sherborne movement and speech and language therapy). Meanwhile, all schools follow the national curriculum (Jordan et al. 1998). Furthermore, schools are working together to 
participate in ASD expertise through working with mainstream, satellite schools and classrooms, where special schools share their experiences in the external community (NAS 2020).

The National Autistic Society (NAS) has been providing specialist autism education in the UK since 1962. They support children and young people in their specialist autism eight schools, ages 4-21 years (As of February 27th, 2020, NAS listed on its website https://www.autism.org.uk/services/nas-schools.aspx).

The present study aims to learn from UK as a good model. The UK has paid great interest to SE practices for children with ASD. That represented in expanding educational opportunities to include inclusion education, developing curricula, supporting health and guidance aspects, launching the comprehensive Education Health Care (EHC) plan, involving parents and sustaining professional development support for SE leaders by laying the foundations of administrative decentralization (Long et al. 2019; DoE 2019; Parkin 2016). The SE practice and EHC plan for children with disabilities in The UK are based on the right policies (Ramsay et al. 2018). Furthermore, UK has unique practice guidelines for children with ASD based on the National Institute for Health and Care Excellence (NICE), Department for Education and Skills and Department of Health UK (Parkin 2016; NICE 2014). Thus, UK can be an example for SE practices for ASD profiles. Considering a comparison to a well-developed education practice is crucial to support the development and delivery of better care for children with ASD in Egypt.

In this context, the purpose of this study is to compare the special education practices for children with ASD in Egypt and UK. The focus is on determining the factors that enhance meeting the educational needs of children with ASD in light of the comparative country (UK). The aim of this is not to make judgments but to examine best practices in SE for ASD that will enhance educational practices in Egypt and evaluate any claim of success. 


\section{Methods}

A comparative analysis is illustrated in this study. Throughout the paper, we describe and compare SE for ASD in the UK and Egypt in the 21st century (20002020). As a comparative examination of SE across two countries, national and international journals, published government reports, and official documents were reviewed in both countries. Databases including ERIC, MEDLINE, Cinhal and PsycINFO (2000- 2020) were searched for articles describing special education with the term 'autism' or 'autism spectrum disorders' and were combined with the term 'Egypt' or 'UK'. All identified relevant reports were searched for additional references.

In line with the aim of the current study, this study was processed according to the comparative method, with the dimension's comparison of historical, descriptive, analytical, cultural, interpretive and predictive. In this, Esser \& Vliegenthart (2017; P.4) and Abod, Hagy and Dahawy (1997; P. 87) outline four steps of comparison, these are:

1. describe the historical development of ASD education in both countries.

2. explore factors that may be important to explain the similarities and differences.

3. identify the similarities and differences considering factors affecting the two countries.

4. explanation and reaching a proposal through which the education for ASD in Egypt could be developed in light of the UK's experiences.

\section{Results}

This study addressed a comparison of special education practices for children with ASD in two contrasting countries, Egypt and UK. The overall goal was to identify factors that are considered effective for successful educational practices for children with ASD in the UK and are commensurate with the possibilities and conditions of Egyptian society. The results suggested some factors which influenced the development of SE practices for children with ASD in the UK and Egypt. UK presented a great 
example of better practice for SE for ASD from which to learn. We present most important developments in SE in the UK and Egypt as follows:

\subsection{Historical Milestones of SE in the $21^{\text {st }}$ Century in Egypt}

Egypt's education system is considered the largest in the Middle East and North Africa region. Egypt is the first Arb country that has shown great interest in SE for blind and deaf pupils (El-Ghunaimi 2002). Major developments in SE in Egypt are briefly presented as follows:

- In 2002, the Egyptian Minister of Education (MoE) announced the 'ministerial inclusion declaration 2002' declared taking the lead to implement inclusive systems in more than 270 schools across Egypt (Ghoneim 2014).

- In 2007, Egypt has contributed to international efforts that culminated in the issuance of the International Convention for the Protection of Persons with Disabilities (Presidential Decree 400).

- In 2009, the MOE further endorsed the move towards inclusion by announcing the right for pupils with mild disabilities to enroll in public and private schools (MoE 2013).

- In 2015, Ministerial decision (No.42) was revealed the integration of children with moderate disabilities in mainstream schools to achieve the inclusive principle in education (MOE 2016).

- In 2018, the Education Ministry sought to integrate students with disabilities and SEN into mainstream schools through Promulgating the Law on the Rights of Persons with Disabilities (No.10). The law mandating that individuals with SEN comprises $5 \%$ of the positions at schools and universities.

- The Egyptian vision 2014-2030 has a new strategic plan for pre-university education in Egypt, including SE. This has a strategic goal to provide pupils with disabilities with high-quality educational opportunities and includes pupils with mild disabilities in all pre-university schools (OECD 2015). 
1.2. Milestones of Special Education in the 21st Century in the UK

The most important developments in SE in the UK are:

- In 2001, the SEN Code of Practice was introduced for children with SEN to maximize their learning.

- $\quad$ In 2003, Every Child Matters legislation aimed to make every child, enjoy his physical and mental health, contribute to society positively and economically (DfES 2003).

- In 2004, the individuals with disabilities education Act was introduced the individualized education plan and all related issues as an example of free and appropriate public education (legislative.gov.uk 2004).

- In 2010, the first autism strategy for people with ASD in UK was published 'Fulfilling and rewarding lives'. The strategy's implementation was included identification, diagnosis of ASD, training of staff and local service provision.

- 2014, Think Autism strategy was published, which was built on the 2010 strategy and set a renewed focus on three key areas: autism aware communities, promoting autism innovation fund in service provision and providing integrated care (Parkin 2016).

- $\quad$ Later in 2014, Education Health Care Plan (EHC) was launched in the UK, which aims to provide more substantial help for children and young people through a unified approach that reaches across education, health care and social care needs (Long et al. 2019). 
Comparison of historical developments milestones of SE in the 21st Century in the UK and Egypt is presented in table 1.

Table (1) Historical Milestones of special education in the $21^{\text {st }}$ Century in the UK and Egypt

\begin{tabular}{|c|c|c|c|}
\hline Year & Egypt & Year & UK \\
\hline 2002 & $\begin{array}{l}\text { The ministerial inclusion } \\
\text { declaration. }\end{array}$ & 2001 & $\begin{array}{l}\text { Special Educational Needs and Disability } \\
\text { Act (2001) and Special Educational Needs } \\
\text { Code of Practice }\end{array}$ \\
\hline 2007 & $\begin{array}{l}\text { International Convention for the } \\
\text { Protection of Persons with } \\
\text { Disabilities }\end{array}$ & 2003 & Every Child Matters legislation, 2003. \\
\hline 2009 & $\begin{array}{l}\text { A Ministerial Act "right for } \\
\text { students with mild disabilities to } \\
\text { enroll in public and private } \\
\text { schools" }\end{array}$ & 2004 & $\begin{array}{l}\text {-Individuals with disabilities education } \\
\text { Act. } \\
\text {-Individuals with Disabilities Education } \\
\text { improvement Act (IDEIA) }\end{array}$ \\
\hline 2015 & $\begin{array}{l}\text { Ministerial decision (No.42) } \\
\text { 'acceptance of children with } \\
\text { moderate disabilities in } \\
\text { mainstream public schools' }\end{array}$ & 2010 & Fulfilling and rewarding lives \\
\hline 2017 & $\begin{array}{l}\text { Inclusion Education for mild } \\
\text { disabilities }\end{array}$ & 2014 & $\begin{array}{l}\text {-Education, Health and Care plan } \\
\text {-Think Autism }\end{array}$ \\
\hline $\begin{array}{l}2014- \\
2030\end{array}$ & Incheon declaration 2030 & -- & -- \\
\hline 2018 & $\begin{array}{c}\text { Law No. 10- Promulgating the } \\
\text { Law on the Rights of Persons with } \\
\text { Disabilities }\end{array}$ & -- & -- \\
\hline
\end{tabular}


1.3. Factors influence developments and innovations in ASD special education in the UK and Egypt.

There are interrelationships between social, cultural, economic status and politics involved in developing SE for children with ASD. These factors can illustrate as follows:

\section{Culture factor}

A cultural belief and stigma associated with ASD may differ in a country with limited resources, Egypt, and a country with substantial ASD resources, UK. Cultural differences in Egypt due to rural/urban and social class dimensions can influence the overall quality of education in general (Megahed et al. 2012). These dimensions can have a negative impact on the overall quality of education in general and on special education of ASD in particular (Obeid et al. 2015). It is also important to emphasis that cultural groups differ with regard to disabilities and behavioural style. Culture can influence the fundamental aspects of education, the likelihood that individuals seek help, how they have been treated and the ability to participate in society. The 'autism strategy' introduced in 2010 had a positive impact on social acceptance and accessible societies for individuals with ASD (Department of Health 2014). Positive and pejorative attitudes were reported in the UK and Egypt (Waldock \& Forrester-Jones 2020; Gobrial 2015). Developing positive attitudes toward ASD will enhance the integration of children with ASD into society and education.

Furthermore, attitudes toward disability may also negatively influence the way people think and act toward disabilities. Stigma and attitudes towards disabilities can have a critical impact on the education of students with special needs. Mothers in Egypt as well as in other Arab countries suffer social stigma and feel sham towards their child with ASD (Sulaimani \& Gut, 2019; Gobrial 2018). Consequently, this could have an unfavourable impact on education, the way they are treated and the ability to participate in society (Gobrial 2015). Moreover, teacher's attitude can influence the enrolment and participation of children with special needs in education (Ismail 2018; Gobrial 2015). Al-Zyoudi (2006) reported a negative attitude of teachers towards the inclusion of 
children with special needs. He illustrated that teachers are more likely to accept children with a physical disability rather than other types with disabilities.

\section{Economic factor}

The economic factor plays a crucial role in shaping SE in a way that countries priorities their services for children with SEN (Preece \& Jordan 2010). Egyptian families are either from lower or higher socio-economic spheres, therefore, Egyptian society suffers from a class gap between people. Poverty rates are $27.8 \%$, with multidimensional poverty among children at $29.5 \%$, so over 10 million in Egypt are living in conditions of multiple privations related to shortage of access to services and support technique (UNICEF 2017). The finance of ASD's in Egypt is scarce and underfunded. It differs significantly from high-income countries as the care and support for people with ASD rely on a household-provider model (Mendoza 2010).

Conversely, Britain is ranked the fifth-largest economy in the world (World Economic Outlook Database 2020). The British economics has a significant impact on the education sector. The UK has taken decisive measures to address SE. The Autism Education Trust has developed a set of school’s autism standards with funding ( $£ 4.5 \mathrm{M})$ from the Department of Education to describe key common factors for good practice for pupils with ASD (DoE 2016). The Government launched an autism innovation fund to develop creative and cost-effective solutions to create new models of good practice and funspecial schools that are equipped with the latest devices and equipment (Parkin 2016).

III. Education policy

The Egyptian government places high priority on disability, with governmental and non-governmental organizations working together to address disability issues. Despite this, the quality of education experience remains low and unequally distributed (World Bank 2007). Moreover, the new policy provision of community care is limited and only available in major cities (Meguid 2014). There were several ministerial decisions, such as ministerial decision No.42, in 2015, which concerned the acceptance 
of children with minor disabilities into general education to achieve an inclusive principle in education.

The Egyptian education vision 2030 'Incheon declaration 2014-2030' involves improving the learning experiences and outcomes of special schools and ensuring quality of life for children with disabilities (Bohl, Hanna, Scott, Moyer and Hedden 2018). Despite the great effort and attention given by the Egyptian government, SE practices for ASD are not yet identified as other disabilities in Egypt. There is no single legislation or regulatory policy present in Egypt that directly pertains to ASD. Therefore, children with ASD in Egypt suffer from the scarcity of autism specialized government schools and the high cost of education and intervention in the private sector. It is a common practice for children with ASD in Egypt to be excluded from enrolment in public schools as well as intellectual disabilities schools, or for those who managed to enroll in school, many of them ended up dropping out and uneducated at home (Gobrial 2018; Costandi 2011).

On the contrary, the UK has better practice guidelines for SE for children with ASD. The education code of practice promoted consistency of approach to meet children's SEN and places the rights of those children with SEN at the heart of the process.

Every Child Matters policy launched in the UK in 2003. The UK government committed to set a plan for children and young people with disabilities and those with complex health needs. This is made clear in Standard 8, of the UK policy to maximise the health and well-being and achievement of all children (DOH 2004). This is in line with the No Child Left Behind Act of 2001 (NCLB) which is the most visible incarnation of federal education policy in the US and democratic societies, which encourages the interest of each child as the center of the educational process (Anderson 2005). 
The new Act for children and families (2014) provided a significant reform of the system for identifying children and young people in The UK with SEN, assessing their needs, and making provision for them (Long et al. 2019). Child with ASD in the UK can attend a school with typically developing children, either in the same classroom, attend a special-education classroom or attend an ASD school. Furthermore, children with ASD are eligible for a free EHC plan and school meals. ASD is considered the most prevalent primary type of need (33\% boys and 18\% girls) with an EHC plan in the UK (DoE 2019).

\section{Technological factor}

Technology and digital learning devices introduce a crucial role in SE for pupils with disabilities. Implementing technology in education can improve skills development, enhances motivation to learn and improves the attention of children with ASD (Mosad 2019). Furthermore, it can help children with ASD manage anxiety or relax while enhancing their abilities to communicate and develop their social skills (Viljoen \& Aranda 2019).

In the UK, digital tools are designed to support the learning process of children with ASD. Existing solutions range from enabling more effective communication of information between educators and students with ASD, providing robot companions to help them feel more comfortable in classroom settings along with facilitating assistive learning with augmented reality (Viljoen \& Aranda 2019).

In Egypt, the outlook for technology use and impact on teaching and learning is the least favourable for various reasons. This includes lack of financial resources and insufficient technical support to maintain ICT tools on an ongoing basis, lack of adequate training in ICT use, the greater overthrow of untrained teachers and the urgent need for pedagogical capacity of the teacher educators (OECD 2015). 
1.4. The comparative analysis of special education practices for ASD in Egypt and UK illustrated some similarities and differences as follows:

\subsubsection{Similarities}

This article has identified that both countries prioritized improving SE practices for children with SEN. However, the UK has specific policies for ASD which is absent in Egypt. The evidence has shown in their interest in legislating strategies and projects which have focused on this aspect. Both Egypt and the UK offer free education for children with SEN.

\subsubsection{Differences}

This review revealed that each country has its unique educational system that has shaped the nature of SE practice. Although Egypt and the UK agreed on some basics, there are still many differences between both counties. First, the education system, the UK's system codifies 12 years, while the Egyptian system codifies only nine years of compulsory education. The concern is not only the number of years but also the law enforcement itself. Egyptian children with ASD are excluded or out of school. There is no concern or punishment if these children drop out of school or are not enrolled due to disabilities. On the contrary, the UK provides special school for children with ASD and a comprehensive EHC plan. There are no special schools for pupils with ASD available in Egypt. Moreover, every pupil with SEN is provided with a teaching assistant and paid by the local authority in the UK, while in Egypt, parents must pay a teaching assistant fee in order for their child to be admitted to school. Additionally, parental involvement in education is considered good in the UK, while this is absent in Egypt (NAS 2020; Aidarous 2016).

Social and cultural awareness of the necessity to focus on school practices for children with ASD enhanced more in the UK than it is in Egypt. This could be due to social growth and prosperity in the UK. On the contrary, Egyptian society is busy solving more crucial issues related to poverty, diseases and unemployment. 
Regarding the financial of SE practices for ASD, this study revealed that the UK overtook Egypt in providing funding for ASD. Evidence shows UK's interest in establishing schools for ASD at all stages. In Egypt, the presence of some centers that concerned with ASD children is limited. These could be due to the different economic situations of these countries.

\section{Discussion}

This study provided useful insights into the relative factors that influenced the developments and innovations of the SE practices in Egypt and the UK. It is critical to emphasize the strong relationship between culture, social deprivation, economics and SEN that deserves careful consideration by the Government in both countries (Parliament UK 2006).

The non-existent education practice for children with ASD in Egypt can have significant consequences for their wellbeing in both the immediate and long-term alongside family wellbeing. Early intervention and education are vital for those children (Koegel et al. 2014). Investing in early intervention for children with ASD can lead to the most critical influences on children's lives, who later can live independently and support themselves and their families. Thus, there is a tremendous need to develop policy strategies to support SE for children with ASD in Egypt and particularly the needs for early intervention. Furthermore, this will increase integration into society for both children and families.

\subsection{Factors enhanced meeting the educational needs of children with ASD}

Given the contextual conditions in each country, Egypt and the UK each has their unique history of SE, which led to different practices for ASD. Many factors could enhance the development of SE practices for any country. Our review revealed several factors that influenced the SE practices for children with ASD in both countries. Economic and social factors had a significant impact on SE in the UK. The legislation and education policies are among the most important factors considered to be a mandatory factor that guided the development of SE in the UK (DoE 2019; 2015). 
However, policies and laws supporting SE practices for ASD were absent in Egypt. Eleweke and Rodda (2002) reported the importance of these policies, which requires: 1) protective safeguards which guarantee the rights of the beneficiary to receive specific services; 2) timed onset and phase plans; 3) consequential effect for non-compliance; 4) room for litigation; 5) accountability, evaluation and monitoring procedures; and 6) financial backing and structure. Furthermore, education policy should be supported by complementary legislation within the field of health, social welfare as currently applied EHC plan in the UK (DOE 2019).

On the contrary, Egypt, lacking the policy framework for children with ASD. The required professional training and skills to implement SE for ASD are undervalued. Therefore, SE practice for ASD is absent, alongside Egypt's low resources and funding for children with ASD, with a shortage of professionals, well-trained special education teachers, and equipped schools. Evidence comes from policy and practice, where regulation is limited. SE practices for children with ASD in Egypt are missing and hindered by policy and poor vision.

The identified factors are consistent with other studies from developing countries and the Middle East (Brown 2005; Gaad 2004; Eleweke and Rodda 2002). Finally, evaluating the the UK and Egypt contexts enabled us to understand the gaps and challenges in Egyptian policy. The originality of the study is that this is the only study that compared and reviewed SE practices for ASD in Egypt and UK. previous comparison studies for SE in both countries have reported only SE in general and focused on intellectual disabilities. However, no studies have looked at SE practices for children with ASD. There are good SE practices for children with ASD, as set in the UK, based on the current review, which can set an example for education practices for ASD. Such education practices could inform further development of ASD education in Egypt.

\subsection{Proposal for developing special education practice for ASD in Egypt}

This study can be beneficial to the development of special education practices in Egypt. With regard the current demand for SE for children with ASD in Egypt, it is 
crucial that the Egyptian Government, the Ministry of Education, and policymakers recognize the scale of the issue and develop a more in-depth understanding of SE that is urgently needed for children with ASD. Given the UK experience, specific actions required include:

1. adequate long-term funding should be provided to establish special schools to meet the growing demand to support children with ASD.

2. Ministry of Education should establish SE for pupils with ASD in all governorates that enhance the children's development and meet their special needs in the classrooms.

3. developing comprehensive education practices and curricula that support health and guidance aspects for ASD that are similar to EHCP in the UK.

4. raise the profile of the profession, provide teachers with the necessary training needed to quality equitable education and promote lifelong learning opportunities for children with ASD by 2030 (Sustainable Development Goal).

5. raising ASD awareness through holding public conferences, seminars, workshops and lectures.

\section{Limitation and Implication}

Lack of previous research studies on SE for ASD practice in Egypt has limited published information available. Future projects could pursue qualitative research to identify the reality of SE practices through an interview or focus group discussions with teachers and parents. Future research in other aspects will provide a complete explanation of how the two countries have developed SE for ASD compared with one another. For example, it is necessary to address the question of why certain popular disabilities like ASD in the UK have not been much addressed in Egypt and what is the implication of the lack of identification. Furthermore, this study has implications for policy and education campaigns. This study clarifies the barriers to SE for ASD in Egypt. Thus, there is an urgent need to advocate for a broader global understanding of the needs of children with ASD and help establish and support educational and 
rehabilitative practices in underserved developing countries. The main implication of this study is that once enhanced factors are identified, holistic frameworks that could successfully implement the adoption of good educational practices for ASD in Egypt. This could serve as a guide for improving SE for other developing countries in the Middle East.

\section{Conclusions}

This study reviewed special education practices for children with ASD and determined some factors that enhanced the development of SE in Egypt and UK. The results indicated that socio-economic, educational policy, resources, awareness, professional development activities and teacher training had the potential to enhance SE practices for children with ASD. SE of ASD in the UK has been enhanced through economy, social and technological development factors. Increased interest in SE in the UK is due to economic recovery, cultural awareness and education policies. This study suggests that socio-economic factors had a critical influence on the development of SE for ASD.

Conversely, SE practice in Egypt was hindered by the low economic status, scarcity of cultural awareness, insufficient financial support, and absence of education policy for ASD. It is a necessity to provide the adequate financial support that is required for developing special schools for ASD in Egypt. Children with ASD who advocate for appropriate services and education can enjoy a better quality of life. SE for those unique children must be met through an adequate SE practice. This study seeks to understand the challenges for SE for ASD in Egypt and to inform decision makers with insights driven from the development of education policies and practices in the UK.

Funding: This research received no external funding.

Conflicts of Interest: The authors declare no conflict of interest. 


\section{References}

Abod, Abd-Elghany., Hagy, Ismaiel and Dahawy, Bioumy. (1997). Comparative Education: Methods and applications. Cairo: Dar-ElFaker El-Araby.

Aidarous, Ahmed. (2016). The management of special education in the Canadian state of Ontario and the Australian state of Victoria and the possibility of benefiting from them in Egypt. Journal of Faculty of Education Benha University 27(107):47-192. http://search.mandumah.com/Record/789584

Al-Ghunaimi, Hamdi. 2002. "The Ministry of Education's Achievements in the field of Special Education during the last five years." International Legislative Council no.70.

Al-Zyoudi, M. (2006). Teachers' attitudes towards inclusive education in Jordanian schools. International Journal of Special Education, 21(2), 55-62.

Anderson, Lee W. (2005). The No Child Left Behind Act and the Legacy of Federal Aid to Education. Education Policy Analysis Archives, 13 (24).1-23. ISSN 1068-2341

BMA (British Medical Association). (2020). Autism spectrum disorders. Available at: https://www.bma.org.uk/what-we-do/population-health/childhealth/autism-spectrum-disorder (accessed 17thMar. 2021).

Bohl, D., Hanna, T., Scott, A., Moyer, J., and Hedden, S. (2018). Sustainable Development Goals Report: Egypt 2030. Denver, Co and New York, NY: Frederick S. Pardee Center for International Futures and United Nations Development Programme. ISBN-13: 978-1-7335865-2-8.

Brown, R. (2005). Inclusive education in Middle Eastern cultures: the challenge of tradition. In Contextualizing inclusive education: evaluating old and new international perspectives, edited by David Mitchell, 253-278. London: Routledge.

CDC (Centers for Disease Control and Prevention). (2020). Prevalence of autism spectrum disorders among children aged 8 years: autism and 
developmental disabilities monitoring network, 11 sites, United States, 2016. MMWR Surveillance Summaries, 69(4):1-12. https://www.cdc.gov/mmwr/volumes/69/ss/ss6904a1.htm?s_cid=ss6904a1_w Chiarotti, F. and Venerosi, A. (2020). Epidemiology of Autism Spectrum Disorders: A Review of Worldwide Prevalence Estimates Since 2014. Brain Sci., 10, 274. https://doi.org/10.3390/brainsci10050274

Costandi, Moheb. (2011). Arab children with autism are beginning to receive the latest education methods developed in the west at new specialized institutes, but the region also has something to offer autism researchers in the rest of the world: consanguineous marriage. Available at: http://www.nature.com/nmiddleeast/2011/012345/full/nmiddleeast.2011.148.html. (accessed 22ndAug. 2019).

Courtenay, K. (2018). Special edition: mental health and intellectual disabilities in Europe", Advances in Mental Health and Intellectual Disabilities,12(3/4):89-90, https://doi.org/10.1108/AMHID-07-2018069

DoE. (Department of Education). (2019). Special educational needs in England. Available at:

https://assets.publishing.service.gov.uk/government/uploads/system/uploads/attachme nt_data/file/814244/SEN_2019_Text.docx.pdf. (accessed 10thDecember 2019).

DoE. (Department of Education). (2015). Special educational needs and disability code of practice $0-25$ years. Available at: https://assets.publishing.service.gov.uk/government/uploads/system/upl oads/attachment_data/file/398815/SEND_Code_of_Practice_January_2 015.pdf. (accessed 31stJanuary 2020).

DoE. (Department of Education) (2011). Support and aspiration: a new approach to special educational needs and disability, March 2011, paragraph 25.

DoE. (2001). "Special Educational Needs - Code of Practice. Department for Education and Skills." Available from 
https://assets.publishing.service.gov.uk/government/uploads/system/uploads/attachme nt_data/file/273877/special_educational_needs_code_of_practice.pdf.

DoH (Department of Health. (2004). Disabled Children and Young People and those with Complex Health Needs: Change for Children - Every Child Matters. National Service Framework for Children, Young People and Maternity Services. London: Crown.

DfES (Department for Education and Skills) (2003). Every Child Matters. Annesley: DfES.https://assets.publishing.service.gov.uk/government/uploads/syste m/uploads/attachment_data/file/272064/5860.pdf

Eleweke, C. and Rodda, Michael. (2002). The challenge of enhancing inclusive education in developing countries. International Journal of Inclusive Education 6(2):113-126. https://doi.org/10.1080/13603110110067190

Esser, F., \& Vliegenthart, R. (2017). Comparative research methods. The International Encyclopedia of Communication Research Methods, Pp. 1-22, edited by Matthes, J., Potter, R., Davis, C. S. London, England: Wiley-Blackwell. https://doi.org/10.1002/9781118901731.iecrm0035

Fathie, Y. (2016). Angels in our midst: autism in Egypt. Retrieved on 20/11/2018 from https://english.ahram.org.eg/NewsContentP/1/198530/Egypt/ Angels-in-our-midst-Autism-in-Egypt.aspx

Jenkins, R., Heshmat, A., Loza, N., Siekkonen, I., \& Sorour, E. (2010). Mental health policy and development in Egypt - Integrating mental health into health sector reforms 2001-9. International Journal of Mental Health Systems, 4(17), 1-11. https://doi.org/10.1186/1752-4458-4-17

Jordan, Rita, Jones Glenys, and Murray Dinah. (1998). Educational intervention for children with autism: A literature review of recent and current research. Norwich: the permission of DFEE on behalf of the controller of her Majesty's stationery office application colegate. research report. No.77. 
Jovanovic, D. \& Ciric, M. (2017). Methodological specifics of comparative research in education. Facta Universitatis, Series: Teaching, Learning and Teacher Education, 1(1),33-42. DOI: 0.22190/FUTLTE170430004J

Gaad, Eman. (2004). Cross-cultural perspectives on the effect of cultural attitudes towards inclusion for children with intellectual disabilities.

International Journal of Inclusive Education 8(3): 311-328. doi: 10.1080/1360311042000194645

Gobrial, Ereny, McAnelly, S. \& Shannon, P. (2019). The Education of Children and young people with Autistic Spectrum Disorders in Egypt. British Journal of Learning Disabilities, 00,1-6. https://doi.org/10.1111/bld.12250

Gobrial, E. (2018). The Lived experiences of mothers of children with the autism spectrum disorders in Egypt. Social Sciences, 7(8), 133. https://doi.org/10.3390/socsci7080133

Gobrial, E. (2012). Mind the gap: the human rights of children with intellectual disabilities in Egypt, Journal of Intellectual Disability Research, 56 (11): 1058 - 1064. doi.org/10.1111/j.1365-2788.2012.01650.x

Ghoneim, Salah. (2014). Requirements for Inclusion of Children with Disabilities in Public Education in Egypt. Journal of Educational and Social Research 4(4):192-199. doi:10.5901/jesr. 2014.v4n4p192.

Ibrahim, N., El-abdeen, A., Zoromba, M. and Haika, A. (2020). Socio-economic and demographic factors associated with adaptive behaviour among children diagnosed with autism spectrum disorder in Egypt. Middle East Current Psychiatry, 27(38) https://doi.org/10.1186/s43045-02000047-8.

Ismail, Asar. (2018). Teachers' Attitudes Toward Including Children with Special Educational Needs in Private Schools in Egypt. The International Academic Forum. The European Conference on Education 2018 Official Conference Proceedings. 
Koegel, L. Kern., Koegel, R.L., Ashbaugh, K. \& Bradshaw, J. (2014). The importance of early identification and intervention for children with or at risk for autism spectrum disorders, International Journal of Speech-Language Pathology, 16:1, 50-56, DOI: 10.3109/17549507.2013.861511

Long, Robert, Roberts, Nerys., and Danechi, Shadi. (2019). Special Educational Needs: support in England. England: House of Commons Library. No. 07020.

Maciver, D., Hunter, Cathleen, Adamson Amanda, Grayson Zoe, Forsyth Kirsty, and McLeod Iona. (2018). Supporting successful inclusive practices for learners with disabilities in high schools: a multisite, mixed method collective case study. Disability and Rehabilitation 40(14):1708-1717. doi: 10.1080/09638288.2017.1306586.

Malgorzata, S. and El-Deabes, Y. (2012). The education system of Egypt: Contexts, frams and structures. Problems of education in the 21 st century, 40 : 129-144. http://www.scientiasocialis.lt/pec/files/pdf/vol40/129144.Stopikowska_Vol.40.pdf

Meguid, Nagwa. (2014). Autism and Egypt: historical Background. Berlin: SpringerVerlag Berlin Heidelberg.

Megahed, Nagwa, Ginsburg Mark, Abdellah Antra, and Zohry Ayman. (2012). The quest for educational quality in Egypt. in book quality and qualities in education reforms, edited by Acedo Clementina, Adams Don, and Popa Simona, 41-67. Netherlands: Sense Publishers.

Mendoza, Roger, and Cherry Hill. (2010). The Economics of Autism in Egypt. American Journal of Economics and Business Administration 2(1):1219. SSRN: https://ssrn.com/abstract=1553452.

Mosad, Amira. (2019). Recent Trends of Educational Technology for Egypt. Journal of Research in Curriculum, Instruction and Educational Technology, 5(3):187-204. https://journals.ekb.eg/article_54148_cb97ce5588080cf3222c82da363e bb0e.pdf 
MOE (Ministry of Education) (2014). National strategic plan for pre-university education in Egypt (2014-2030) Education Egypt National Project. Retrieved from UNESCO:http://www.unesco.org/education/edurights/media/docs/c33b 72f4c03c58424c5ff58cc6ae aee0eb58de4.pdf

NAS (National Autistic Society) (2020). Autism and Education: good practice guide. Supporting autistic children in your area. A guide for local authorities and school in England. AXCIS. London. Available at: https://www.autism.org.uk/ /media/nas/professionals/teachers/nas_edu cation_good_practice_guide_web_final.ashx?la=en-gb. (accessed 7thJan. 2020).

National Education Association. (2003). Status of the American Public-School Teacher 2000-2001. Washington, DC: Author.

National Institute for Health and Care Excellence (NICE) (2014). Autism, quality standard [QS51]. Retrieved from https://www.nice.org.uk/guidance/qs51

Obeid, Rita, Daou Nidal, Daou DeNigris, Danielle Simpson Christina, Patricia Brooks, and Lynch Gillespie. (2015). A Cross-Cultural Comparison of Knowledge and Stigma Associated with Autism Spectrum Disorder Among College Students in Lebanon and the United States. Journal of Autism and Developmental Disorders, 45(11):3520-3536. doi: 10.1007/s10803-015-2499-1.

OECD. (2015). "Schools for skills: a new learning agenda for Egypt. better policies for better lives". OECD, France.

Omar, Tarek, Ahmed, Wafaa \& Basiouny, Nehads. (2017). Challenges and adjustments of mothers having children with autism. Alexandria Journal of Pediatrics 30 (3), 120-129. DOI:10.4103/AJOP.AJOP_4_18.

Parkin, Elizabeth. (2016). Autism overview of UK: policy and services. Westminster. London: House of commons library. 
Parliament.UK. (2006). Education and skills. Available at: https://publications.parliament.uk/pa/cm200506/cmselect/cmeduski/478 147806.htm. (accessed 9th January 2020).

Preece, David, and Jordan, Rita. (2010). Obtaining the views of children and young people with autism spectrum disorders about their experience of daily life and social care support. British Journal of Learning Disabilities, 38(1):10-20. https://doi.org/10.1111/j.1468-3156.2009.00548.x

Social Care, Local Government, Care Partnership Directorate, and Department of Health. (2014). Think Autism Fulfilling and Rewarding Lives, the strategy for adults with autism in England: an update.UK: Crown. Special Educational Needs and Disability Act (2001). Part 1 Special educational needs. Available at: http://www.legislation.gov.uk/ukpga/2001/10/contents (accessed 12thMar. 2020).

Sulaimani, M. \& Gut, D. (2019). Dealing with Shame: Saudi Mothers' Responses to Their Children's Diagnosis of Autism Spectrum Disorder. Review disability studies: An International Journal, Forum - Disability and Shame, 15(3), 1-18.

Taha, G.\& Hussein, H. (2014). Autism spectrum disorders in developing countries: Lessons from the Arab world. Comprehensive Guide to Autism, 25092531.

The Secretary of State for Justice and Lord Chancellor by Command of Her Majesty. (2007). The Governance of Britain: presented to Parliament. UK: Crown.

UNESCO (United Nations Educational, Scientific and Cultural Organization). (1994). The Salamanca statement and framework for action on special needs education. Salamanca. Available at: http:// www.unesco.org/education/pdf/SALAMA_E.PDF (accessed 10thSeptember 2019). 
UNICEF (United Nations International Children's Emergency Fund). (1989). The United Nations Convention on the Rights of the Child. London:

UNICEF. Available at: http://www.unicef.org.uk/Documents/ (accessed 5thSeptember 2019).

UNICEF. (2014). Annual Report 2014 outlines UNICEF's ongoing efforts to realize the rights of every child, especially the most disadvantaged, and break the intergenerational cycle of inequity and poverty.

UNICEF. (2017). UNICEF Annual Report 2017, 2017, p.1.

Viljoen, K. \& Aranda, C. (2019). Digital technologies supporting persons on the autism spectrum. Available at: https://www.gsma.com/mobilefordevelopment/blog/digitaltechnologies-supporting-persons-on-the-autism-spectrum (accessed 4thOct.2020).

Waldock, K., \& Forrester-Jones, R. (2020). An exploratory study of attitudes towards autism amongst church-going Christians in the South East of England, United Kingdom. Journal of Disability \& Religion, 24(4), 349370. https://doi.org/10.1080/23312521.2020.1776667

Warnock, M. (1978) Report of the Committee of Enquiry into the Education of Handicapped Children and Young People. London: HMSO. Warnock, M. (2005) Special educational needs: a new look. London: Philosophy of Education Society of Great Britain. https://www.specialeducationalneeds.co.uk/warnock--sen.html World Economic Outlook Database. (2020). IMF.org. International Monetary Fund. (accessed 13thMar. 2020).

World Bank. (2007). Improving Our Quality, Equality, and Efficiency in the Education Sector: Fostering a Competent Generation of Youth." Education Sector Policy Note. The World Bank, Washington, D.C. p. 5. (accessed 18thMar. 2021). 